\title{
Pengaruh Kebijakan Sistem Jaringan Transportasi Darat Melalui Type Kebijakan Push and Pull Policy dan Dampaknya terhadap Perekonomian Kota Makassar
}

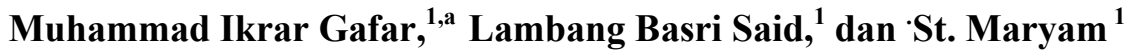 \\ ${ }^{1}$ Magister Teknik Sipil Universitas Muslim Indonesia, Makassar, Sulawesi Selatan \\ aikrar_gaffar@yahoo.com
}

\section{(1) (9)}

Abstract-This study aims to analyze the effect of push and Pull policy $(\mathrm{X})$ as an independent variable both partially and simultaneously on equitable economic development (Y1) and improve people's living standards (Y2) in Makassar City as the dependent variable. This research method uses a questionnaire with 50 respondents as a sample and has been selected from the population that has been selected based on sample criteria that have been determined. Sampling in this study are respondents which are chosen by researchers who reflect all stakeholders and elements of the community of Makassar City from various departments or fields of expertise, understanding and the problems related person. To measure variables, Likert Scale technique is used with scale weights from 1 to 5 . To find out the correlation between variables $X$ to $Y$, statistical techniques using Smart software PLS (Partial Least Square) is employed. The results of the study concluded that there was a significant positive effect of each independent variable on the dependent variable, namely the push and Pull policy $(X)$ policy as an independent variable, partially or simultaneously influencing equal economic development (Y1) and improving people's living standards (Y2) in Makassar City.

Keywords-Push and pull policy; economic development; improvement of living standards.

\footnotetext{
Abstrak-Penelitian ini bertujuan untuk menganalisis pengaruh kebijakan push dan pull policy (X) sebagai variabel independen baik secara parsial maupun simultan terhadap pembangunan ekonomi yang merata (Y1) dan meningkatkan standar kehidupan masyarakat (Y2) di Kota Makassar sebagai variabel dependen. Metode penelitian ini menggunakan kuesioner dengan 50 responden sebagai sampel dan telah dipilih dari populasi yang telah dipilih berdasarkan kriteria sampel yang telah ditentukan pengambilan sampel dalam penelitian ini adalah responden yang dipilih oleh peneliti yang mencerminkan semua pemangku kepentingan dan elemen masyarakat. Kota Makassar. dari berbagai departemen atau bidang keahlian, pemahaman, penguasaan masalah dan pertanyaan yang akan ditanyakan. Pengukuran variabel menggunakan teknik Skala Likert dengan skala bobot dari 1 hingga 5 . Untuk mengetahui korelasi antara variabel $x$ hingga $Y$ menggunakan teknik statistik menggunakan perangkat lunak Smart PLS (Partial Least Square). Hasil penelitian menyimpulkan bahwa ada pengaruh positif yang signifikan dari
}

masing-masing variabel independen terhadap variabel dependen, yaitu kebijakan push dan pull policy (X) sebagai variabel independen, secara parsial atau simultan mempengaruhi pembangunan ekonomi yang sama (Y1) dan meningkatkan standar hidup (Y2) di Kota Makassar.

Kata kunci-Kebijakan push dan pull; pertumbuhan ekonomi; peningkatan standar hidup.

\section{Pendahuluan}

Masalah transportasi berbeda dengan masalah lain yang dihadapi oleh masyarakat yang sedang berkembang. Transportasi adalah tulang punggung dalam menciptakan kesejahteraan masyarakat [1]. Oleh karena itu, jika ada masalah dalam sistem transportasi, itu akan berdampak pada kelancaran arus lalu lintas dan pada akhirnya akan menghambat pencapaian kesejahteraan masyarakat. Lebih lanjut dalam referensi [2] dijelaskan bahwa dalam mencapai pembangunan suatu wilayah, peran transportasi darat memiliki posisi penting dan strategis, sehingga kebijakan perlu diintegrasikan dalam kebijakan manajemen tunggal dan dampak transportasi darat terhadap perekonomian masyarakat. London, Singapura, Portland, dan Curitiba adalah contoh praktik yang baik di tingkat pemerintah, setelah mencapai angkutan umum yang andal dan terintegrasi. Kebijakan untuk meningkatkan penggunaan angkutan umum harus menjadi bagian dari kebijakan terpadu. Kebijakan terintegrasi mengacu pada integrasi lintas moda transportasi yang berbeda, tujuan pemerintah yang berbeda (seperti ekonomi, kesehatan dan lingkungan), mempertimbangkan kebutuhan berbagai kelompok sosial, dan tindakan koordinasi 
antara lembaga pemerintah terkait [3]. Ada bukti bahwa kurangnya koordinasi dapat membahayakan pencapaian tujuan kebijakan.

Transportasi darat merupakan moda transportasi yang paling dominan di Indonesia dibandingkan moda tranportasi lainnya seperti transportasi udara dan transportasi laut. Hal ini ditunjukkan dari data OD Nasional 2017 yang menggambarkan bahwa \pm 95\% perjalanan penumpang dan barang menggunakan moda transportasi darat. Besarnya persentase tersebut merefleksikan tingginya ketergantungan penduduk Indonesia terhadap moda transportasi ini. Oleh sebab itu, perencanaan pengembangan transportasi darat menjadi prioritas utama dalam rangka pembangunan Indonesia secara keseluruhan. Kebijakan pengembangan transportasi darat dibutuhkan tidak hanya untuk mengatasi permasalahan transportasi yang terjadi saat ini, tetapi juga untuk menjawab permasalahan transportasi yang diperkirakan muncul di masa yang akan datang [4].

Makassar merupakan salah satu kota yang mengalami kemajuan yang pesat, dalam pencapaian pembangunannya, peranan transportasi darat di Kota Makassar memiliki posisi penting dan strategis, sehingga kebijakan transportasi darat di Kota Makassar perlu ditata dalam satu kesatuan kebijakan transportasi darat dan pertumbuhan perekonomian masyarakat. Tingginya kepemilikan kendaraan pribadi yang ditandai dengan pertumbuhan kendaraan pribadi yang cukup pesat yaitu mencapai angka 6.700 unit kendaraan perbulan (Samsat Makassar), menandakan bahwa angkutan umum di kota ini masih kalah pamor dibandingkan dengan kendaraan pribadi. Padahal angkutan umum utama di kota ini yang berupa metromini (pete'-pete') memiliki jumlah sebesar 4.113 unit [5] yang tersebar dan melayani jalan-jalan utama yang ada di Kota Makassar. Hal ini tentunya memberikan gambaran bahwa jumlah angkutan umum yang ada di Kota Makassar ternyata juga cukup banyak. Untuk jalan-jalan lingkungan terdapat beberapa angkutan umum alternatif yaitu ojek, becak, dan yang saat ini sedang populer di lingkungan permukiman adalah angkutan becak motor (bentor) dengan jumlah sekitar 1.000 unit yang tersebar hampir di setiap sudut permukiman Kota Makassar [5].
Salah satu upaya untuk mengurai kemacetan Kota yaitu melalui kebijakan push and pull policy. Kementerian Perhubungan Republik Indonesia, (2011) menyatakan bahwa untuk membenahi transportasi perkotaan, salah satu cara yang dilakukan pemerintah melalui kebijakan push and pull policy, membuat daya tarik (pull policy). Pull itu daya tarik dari angkutan umum agar mampu menarik mereka yang memakai kendaraan pribadi untuk menggunakan kendaraan umum. Sedangkan push policy adalah bagaimana caranya mereka yang menggunakan kendaraan itu benarbenar merasakan kendaraan pribadi ini membayar sesuai dengan apa yang dilakukan. Artinya mereka harus aware terhadap semua dampak yang ditimbulkan kalau mereka menggunakan kendaraan pribadi," penjabaran dari kebijakan pull policy, yaitu agar angkutan umum mampu menarik masyarakat yang memakai kendaraan pribadi untuk menggunakan kendaraan umum. Selain itu, menurut Zico [6], strategi push and pull policy ini bisa diterapkan dengan cara menaikan pajak kendaraan dengan signifikan sehingga masyarakat akan berpikir ulang untuk membeli kendaraan. Kebijakan tersebut terbukti ampuh di beberapa negara maju semisal Singapura. Adapun untuk mendukung sistem pull ini maka tarif parkir dalam kota seperti di pusat perbelanjaan, perkantoran, dan lain-lain harus dinaikan.

Dalam pencapaian pembangunan di Kota Makassar, peranan transportasi darat memiliki posisi penting dan strategis, sehingga kebijakan transportasi darat perlu ditata dalam satu kesatuan kebijakan transportasi darat dan pertumbuhan perekonomian masyarakat. Sharma dan Kumar [7], menjelaskan bahwa berhasil atau tidaknya regulasi yang telah diterapkan untuk mengatasi masalah kemacetan di ruas jalan ini akan memberikan gambaran mengenai keberhasilan fungsi dari regulasi itu sendiri.

Regulasi yang baik haruslah regulasi yang mampu untuk mengatasi persoalan yang ada dan memperbaiki masalah tersebut ke arah yang lebih baik. Oleh sebab itu, bila terjadi problem dalam sistem transportasi, maka, hal tersebut akan berdampak luas pada kelancaran lalulintas dan pada akhirnya akan menghambat dan merugikan kegiatan perekonomian masyarakat, dan upaya pencapaian kesejahteraan masyarakat pun turut 
terhambat. Berdasarkan uraian tersebut di atas, penulis mencoba untuk menganalisis dan membahas tentang kebijakan push and pull policy di Kota Makassar, dengan judul "pengaruh kebijakan sistem jaringan transportasi darat melalui type kebijakan push and pull policy terhadap perekonomian Kota Makassar". Adapun tujuan penelitian ini untuk menganalisis pengaruh kebijakan push and pull policy terhadap pembangunan ekonomi yang merata serta meningkatkan taraf hidup rakyat di Kota Makassar.

\section{Metode Penelitian}

Sesuai dengan hipotesis yang telah dirumuskan, maka dalam penelitian ini analisis data statistik inferensial diukur dengan menggunakan software Smart PLS (Partial Least Square) mulai dari pengukuran model (outer model), struktur model (inner model) dan pengujian hipotesis. Adapun lokasi penelitian dilaksanakan di Kota Makassar, lokasi penelitian ini dipilih dengan pertimbangan bahwa peneliti mudah memperoleh data penelitian baik yang bersifat data primer dari responden. Waktu penelitian dilaksanakan selama dua bulan mulai Januari- Februari 2019. Jumlah sampel yang digunakan pada penelitian ini sebanyak 50 sampel dari kalangan birokrat, kalangan Pengatur Lalulintas dan DLLAJR (Dinas Lalu Lintas dan Jalan Raya), dari kalangan akademisi dan kalangan pengusaha, sebagai penyedia infrastruktur transportasi umum di Kota Makassar yang juga mewakili kalangan para supir angkot dan pedagang kaki lima.

\section{Hasil dan Pembahasan}

\section{a. Evaluasi Measurement (Outer) Model}

\section{Convergent Validity}

Pada penelitian ini akan dilakukan pengujian validitas dan reliabilitas pada masing-masing variabel laten yaitu variabel kebijakan push and pull policy, pembangunan ekonomi yang merata dan peningkatan taraf hidup rakyat dengan menggunakan bantuan software SmartPLS. Ukuran refleksif individual dikatakan valid jika memiliki nilai loading dengan variabel laten yang ingin diukur $\geq 0.5$, jika salah satu indikator memiliki nilai loading $<0.5$ maka indikator tersebut harus dibuang (di-drop) karena akan mengindikasikan bahwa indikator tidak cukup baik untuk mengukur variabel laten secara tepat. Berdasarkan hasil pengujian awal pada Gambar 1 model penelitian ini menunjukkan variabel y2.4 dengan nilai loading faktor dibawah 0,5 yaitu hanya sebesar 0,426 yang tidak memenuhi persayaratan sehingga harus dikeluarkan dari model penelitian dan dilakukan uji tahap kedua.

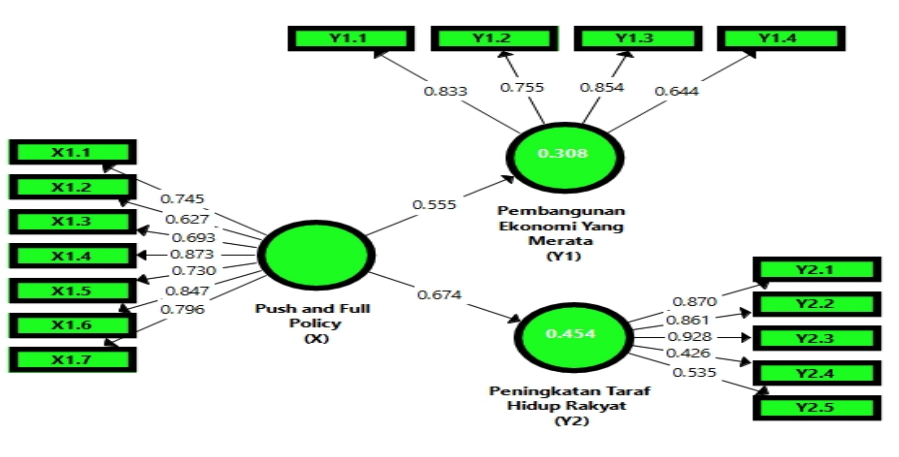

Gambar 1. Model Uji Awal Outer Loadings

Berdasarkan Hasil pengolahan dengan menggunakan SmartPLS beberapa outer indikator yang sudah memenuhi persyaratan. Sedangkan pada gambar 2, menunjukkan nilai outer model atau korelasi antara konstruk dengan variabel telah memenuhi convergen validity karena penyebaran nilai loading factor yang nilainya memiliki loading factor di atas 0.50 yang menunjukkan bahwa semua loading factor telah valid.

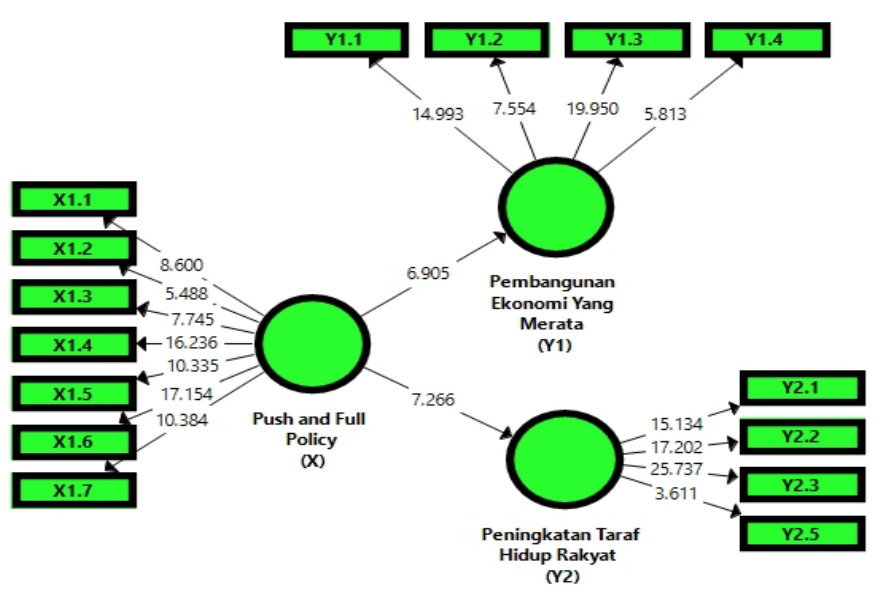

Gambar 2. Model Uji Tahap Kedua Outer Loadings

Hasil pengolahan dengan menggunakan SmartPLS dapat dilihat pada gambar 2. Nilai outer model atau korelasi antara konstruk dengan variabel pada awalnya 
telah memenuhi convergen validity karena model penelitian ini menunjukkan outer indikator yang sudah memenuhi pernyaratan, karena indikator loading factornya masih berada diatas standar loading dengan variabel laten yang ingin diukur $\geq 0.5$.

\section{Discriminate Validity}

Discriminant validity dilakukan untuk memastikan bahwa setiap konsep dari masing variabel laten berbeda dengan variabel lainnya. Model mempunyai discriminant validity yang baik jika setiap nilai loading dari setiap indikator dari sebuah variabel laten memiliki nilai loading yang paling besar dengan nilai loading lain terhadap variabel laten lainnya. Pengujian discriminant validity dilakukan untuk membuktikan apakah indikator pada suatu konstruk akan mempunyai loading factor terbesar pada konstruk yang dibentuknya dari pada loading factor dengan konstruk yang lain. Dapat di lihat cross loading pada tabel 1 berikut:

\begin{tabular}{|c|c|c|c|}
\hline \multicolumn{1}{|c}{ Tabel 1 Cross Loading } \\
\hline & $\begin{array}{c}\text { Push and } \\
\text { Pull Policy } \\
\text { X) }\end{array}$ & $\begin{array}{c}\text { Pembangunan } \\
\text { Ekonomi Yang } \\
\text { Merata (Y1) }\end{array}$ & $\begin{array}{c}\text { Peningkatan } \\
\text { Taraf Hidup } \\
\text { Rakyat (Y2) }\end{array}$ \\
\hline X1.1 & $\mathbf{0 . 7 4 4}$ & 0.499 & 0.549 \\
\hline X1.2 & $\mathbf{0 . 6 2 6}$ & 0.274 & 0.387 \\
\hline X1.3 & $\mathbf{0 . 6 9 2}$ & 0.347 & 0.531 \\
\hline X1.4 & $\mathbf{0 . 8 7 3}$ & 0.383 & 0.595 \\
\hline X1.5 & $\mathbf{0 . 7 3 0}$ & 0.392 & 0.389 \\
\hline X1.6 & $\mathbf{0 . 8 4 8}$ & 0.490 & 0.607 \\
\hline X1.7 & $\mathbf{0 . 7 9 7}$ & 0.521 & 0.534 \\
\hline Y1.1 & 0.440 & $\mathbf{0 . 8 3 3}$ & 0.548 \\
\hline Y1.2 & 0.369 & $\mathbf{0 . 7 5 5}$ & 0.404 \\
\hline Y1.3 & 0.549 & $\mathbf{0 . 8 5 4}$ & 0.484 \\
\hline Y1.4 & 0.318 & $\mathbf{0 . 6 4 4}$ & 0.419 \\
\hline Y2.1 & 0.590 & 0.598 & $\mathbf{0 . 8 7 1}$ \\
\hline Y2.2 & 0.681 & 0.470 & $\mathbf{0 . 8 6 9}$ \\
\hline Y2.3 & 0.590 & 0.520 & $\mathbf{0 . 9 2 7}$ \\
\hline Y2.5 & 0.225 & 0.352 & $\mathbf{0 . 5 2 4}$ \\
\hline & & & \\
\hline
\end{tabular}

Berdasarkan tabel 1, terlihat adanya discriminate validity yang baik oleh karena nilai korelasi indikator terhadap konstruknya lebih tinggi dibandingkan nilai kolerasi indikator dengan konstruk lainnya. Tabel tersebut juga menunjukkan bahwa indikator-indikator dari variabel laten lainnya kebijakan push and pull policy, pembangunan ekonomi yang merata dan peningkatan taraf hidup rakyat juga mempunyai nilai loading factor yang lebih tinggi daripada loading factor dengan konstruk yang lain.

\section{Composite Reliability dan Cronbach's Alpha}

Disamping uji validitas konstruk, dilakukan juga uji reliabilitas konstruk yang diukur dengan composite reliability dan cronbach's alpha dari blok indikator yang mengukur konstruk. Berikut ini adalah hasil pengujian composite reliability dari Smart PLS.

Tabel 2 Composite Reliability dan Cronbach's Alpha

\begin{tabular}{|c|c|}
\hline Variabel Laten & $\begin{array}{c}\text { Reliabilitas } \\
\text { Komposit }\end{array}$ \\
\hline Pembangunan Ekonomi yang Merata (Y1) & 0.857 \\
\hline Peningkatan Taraf Hidup Rakyat (Y2) & 0.883 \\
\hline Push and Pull Policy (X) & 0.906 \\
\hline
\end{tabular}

Konstruksi dinyatakan reliabel jika memiliki nilai composite reliability di atas 0,70. Dari hasil output SmartPLS di atas semua konstruk memiliki nilai composite reliability di atas 0,70 . Jadi dapat disimpulkan bahwa konstruk memiliki realiabilitas yang baik.

\section{b. Pengujian Model Struktural (Inner Model)}

Uji signifikansi model mengunakan teknik boostraping dengan hasilnya dapat dilihat pada Tabel 3 di bawah ini dan pada gambar model menunjukkan nilai $\mathrm{t}$ statistic dari habungan antara variabel yang akan dibandingkan dengan nilai t table.

Berdasarkan Tabel 2 terlihat beberapa koefisien sebagai berikut:

1. Koefisien sebesar 0.555 menunjukkan bahwa pengaruh push and pull policy terhadap pembangunan ekonomi yang merata adalah positif. Berdasarkan nilai koefisien dapat disimpulkan bahwa kualitas sumber daya manusia memberikan pengaruh yang signifikan terhadap pembangunan ekonomi yang merata di Kota Makassar dengan tingkat signifikansi 0.000 . 
2. Koefisien sebesar 0.684 menunjukkan bahwa pengaruh push and pull policy terhadap peningkatan taraf hidup rakyat adalah positif. Berdasarkan nilai koefisien dapat disimpulkan bahwa kualitas sumber daya manusia memberikan pengaruh yang signifikan terhadap peningkatan taraf hidup rakyat di Kota Makassar dengan tingkat signifikansi 0.000.

\section{c. Koefisien Determinan}

Koefisien determinan (R2) pada intinya mengukur seberapa kemampuan model dalam menerangkan variabel terikat. Koefisien determinan berkisar antara 0 (nol) sampai dengan 1 (satu), Jika R2 semakin besar, maka dapat dikatakan bahwa pengaruh variabel eksogen (X) adalah besar terhadap variabel endogen (Y). Hal ini berarti model yang digunakan semakin kuat untuk menerangkan pengaruh variabel eksogen yang diteliti terhadap variabel endogen, Sebaliknya, jika R2 semakin mengecil (mendekati nol) maka dapat dikatakan bahwa pengaruh eksogen terhadap variabel endogen, semakin mengecil. Hal ini berarti model yang digunakan tidak kuat untuk menerangkan pengaruh variabel bebas (eksogen) yang diteliti terhadap variabel terikat (endogen). Nilai dari koefisien determinasinya $\left(\mathrm{R}^{2}\right)$ dijelaskan pada tabel 3 berikut ini.

Tabel 3. R Square Adjusted

\begin{tabular}{|c|c|}
\hline & R Square \\
\hline $\begin{array}{c}\text { Pembangunan Ekonomi yang } \\
\text { Merata (Y1) }\end{array}$ & 0.308 \\
\hline $\begin{array}{c}\text { Peningkatan Taraf Hidup Rakyat } \\
\text { (Y2) }\end{array}$ & 0.467 \\
\hline
\end{tabular}

Berdasarkan Tabel 3 menjelaskan nilai $\mathrm{R}^{2}$ sebagai berikut:

1. Pembangunan ekonomi yang merata (y1) memliki nilai koefisien determinasinya $\left(\mathrm{R}^{2}\right)$ sebesar 0,308 yang berarti variabilitas pembangunan ekonomi yang merata yang dapat dijelaskan oleh variabilitas variabel push and pull policy, sebesar 30,8 persen, atau dengan kata lain kontribusi pengaruh push and pull policy terhadap pembangunan ekonomi yang merata di Kota Makassar sebesar 30,8\%, sedangkan sisanya sebesar $69,2 \%$ merupakan kontribusi variabel lain diluar penelitian ini.
2. Peningkatan taraf hidup rakyat (y2) memliki nilai koefisien determinasinya $\left(\mathrm{R}^{2}\right)$ sebesar 0,467 yang berarti variabilitas peningkatan taraf hidup rakyat yang dapat dijelaskan oleh variabilitas variabel push and pull policy, sebesar 46,7 persen, atau dengan kata lain kontribusi pengaruh push and pull policy terhadap peningkatan taraf hidup rakyat di Kota Makassar sebesar 46,7\% sedangkan sisanya sebesar $53.3 \%$ merupakan kontribusi variabel lain diluar penelitian ini.

\section{Pembahasan}

A. Push and pull policy berpengaruh terhadap pembangunan ekonomi yang merata di Kota Makassar.

Kebijakan Push and pull policy berpengaruh positif terhadap pembangunan ekonomi yang merata di Kota Makassar. Hal ini dapat disimpulkan bahwa transportasi dan perekonomian memiliki keterkaitan yang erat, sejalan dengan hasil penelitian Giovanni Siburian [8], hasil penelitian menunjukkan bahwa panjang jalan, jumlah kendaraan bermotor dan pengeluaran pemerintah untuk sektor transportasi darat berpengaruh positif dan signifikan terhadap pertumbuhan ekonomi Indonesia. Hasil penelitian tersebut mendukung paradigma infrastructure led growth. Selanjutnya, hasil estimasi juga mengindikasikan pentingnya dukungan anggaran pemerintah dalam penyediaan infrastruktur yang memadai. Infrastruktur yang baik, pada akhirnya akan memberikan pengaruh positif terhadap aktivitas ekonomi lain. Konsisten pula dengan hasil penelitian Hoin [9], hasilnya menunjukkan bahwa Peran sektor transportasi darat akan mempengaruhi tingkat pendapatan daerah. Retribusi sektor transportasi darat adalah salah satu kemampuan daerah untuk melaksanakan otonomi dalam hal kemampuan keuangan daerah (2). Meningkatkan pertumbuhan ekonomi, tingkat penarikan, pajak, dan biaya lainnya yang ada di sektor transportasi jalan dalam rangka mempercepat pertumbuhan ekonomi.

Untuk membenahi transportasi perkotaan pemerintah harus lebih mengoptimalkan kebijakan pull policy. Pull itu daya tarik dari angkutan umum agar mampu menarik masyarakat yang memakai kendaraan pribadi 
untuk menggunakan kendaraan umum. Sedangkan push policy adalah bagaimana caranya mereka yang menggunakan kendaraan itu benar-benar merasakan kendaraan pribadi ini membayar sesuai dengan apa yang dilakukan Regi [10]. Artinya masyarakat harus menyadari semua dampak yang ditimbulkan kalau mereka menggunakan kendaraan pribadi, sehingga angkutan umum ini bisa menarik masyarakat yang biasa naik kendaraan pribadi. Sebagai hasil akhirnya adalah terwujudnya sistem transportasi massal sebagai upaya pembenahan transportasi perkotaan.

\section{B. Push and pull policy berpengaruh terhadap peningkatan taraf hidup rakyat di Kota Makassar.}

Kebijakan Push and pull policy berpengaruh positif terhadap peningkatan taraf hidup rakyat di Kota Makassar. Hal ini menunjukan bahwa pertumbuhan ekonomi memiliki keterkaitan dengan transportasi, karena akibat pertumbuhan ekonomi maka mobilitas seseorang meningkat dan kebutuhan pergerakannya pun menjadi meningkat melebih kapasitas prasarana transportasi yang tersedia sehingga meningkatkan taraf hidup mayarakat dengan mengurangi kerugian atas persoalan kemacetan, sehingga pemerintah dapat menerapkan strategi berupa push (dorong) and pull (tarik). Sejalan dengan penelitian dengan temuan utama dapat diringkas sebagai berikut. Kebijakan fisik: Peningkatan penggunaan angkutan umum, dikombinasikan dengan penurunan penggunaan mobil pribadi, dapat mengurangi kemacetan lalu lintas dan, yang lebih penting, emisi karbon dioksida (CO2), karena angkutan umum umumnya menyebabkan emisi $\mathrm{CO} 2$ yang lebih rendah per kilometer penumpang daripada mobil pribadi. Tarif angkutan umum disubsidi di sebagian besar tempat, yang dapat dibenarkan oleh skala ekonomi dan oleh kenyataan bahwa angkutan umum dapat mengurangi total eksternalitas angkutan jalan. Konsisten pula dengan hasil penelitian Mulley \& Tsai [11] dimana hasil penelitian memberikan bukti kepada pihak pemerintah untuk merencanakan masa depan sistem Bus Rapid Transit (BRT) di Sydney, Australia. dan untuk mengukur potensi meningkatkan taraf hidup masyarakat terhadap peningkatan transportasi publik melalui peningkatan nilai tanah.
Hal ini seperti ungkapan bahwa transportasi dapat mendorong peningkatan kegiatan ekonomi suatu daerah, karena dengan adanya infrastruktur transportasi maka suatu daerah dapat meningkat kegiatan ekonominya. Namun di sisi lain, akibat tingginya kegiatan ekonomi dimana pertumbuhan ekonomi meningkat maka akan timbul masalah transportasi, karena terjadinya kemacetan lalu lintas, sehingga perlunya penambahan jalur transportasi untuk mengimbangi tingginya kegiatan ekonomi tersebut.

\section{Kesimpulan}

Kesimpulan dari hasil penelitian ini dapat dielaborasi sebagai berikut:

1. Kebijakan Push and pull policy berpengaruh positif terhadap pembangunan ekonomi yang merata di Kota Makassar. Hal ini menunjukan bahwa untuk membenahi transportasi perkotaan pemerintah harus lebih mengoptimalkan kebijakan pull policy. Pull itu daya tarik dari angkutan umum agar mampu menarik masyarakat yang memakai kendaraan pribadi untuk menggunakan kendaraan umum sehingga arah dan kebijakan pembangunan sektor transportasi pada dasarnya merupakan upaya untuk meningkatkan taraf hidup rakyat, merangsang pembangunan ekonomi yang lebih merata di seluruh wilayah

2. Kebijakan Push and pull policy berpengaruh positif terhadap peningkatan taraf hidup rakyat di Kota Makassar, peningkatan jumlah kendaraan menunjukkan pertumbuhan ekonomi suatu daerah, akibat pertumbuhan ekonomi maka mobilitas seseorang meningkat dan kebutuhan pergerakannya pun menjadi meningkat melebih kapasitas prasarana transportasi yang tersedia. Melalui kebijakan Push and pull policy dengan menekan jumlah kendaraaan pribadi untuk mengatasi masalah kemacetan yang dapat menyebabkan banyak kerugian, seperti pemborosan bbm, waktu yang banyak terbuang percuma akibat macet, sehingga keberhasilan kebijakan ini dapat mengurangi problem yang ada dan lebih meningkatkan taraf hidup masyarakat, karena aktivitas masyarakat menjadi lancar. 
3. Untuk mengurangi kerugian atas persoalan kemacetan, diharapkan pemerintah lebih meperhatikan untuk penerapan kebijakan strategi berupa push and pull policy yang dibarengi kebijakan lainnya untuk membatasi jumlah kendaraan sebagai alternatif untuk mengatasi atau mengurangi persoalan kemacetan di berbagai daerah atau diharapkan perlunya penambahan jalur transportasi untuk mengimbangi tingginya kegiatan ekonomi masyarakat.

4. Ketersediaan fasilitas transportasi umum mutlak diselenggarakan pemerintah kota untuk memenuhi kebutuhan mobilitas warga yang semakin meningkat. Oleh karena itu diharapkan kinerja pelayanan angkutan umum harus lebih ditingkatkan agar masyarakat lebih cendrung beralih mengunakan angkutan umum dibandingkan menggunakan angkutan pribadi.

\section{Ucapan Terima Kasih}

Terima Kasih Kami ucapkan kepada Ir. H. Lambang Basri Said, M.T., Ph.D dan Dr. Ir. Hj. St. Maryam, H., M.T. yang telah memberikan bimbingan, bantuan, dukungan dan motivasi dalam penulisan jurnal ini dan juga kepada Kepala Dinas Perhubungan Kota Makassar beserta seluruh staf yang telah membantu terima kasih atas bantuannya yang telah memberikan ijin untuk melakukan pelaksanaan penelitian ini dan terima kasih kepada seluruh responden yang telah membantu pengisian kuesioner penelitian ini.

\section{Daftar Pustaka}

[1] Kadarisman, M., Gunawan, A., \& Ismiyati, I. (2017a). Implementasi Kebijakan Sistem Transportasi Darat Dan Dampaknya Terhadap Kesejahteraan Sosial Di Jakarta. Jurnal Manajemen Transportasi Dan Logistik. https://doi.org/10.25292/j.mtl.v2i1.129

[2] Kadarisman, M., Gunawan, A., \& Ismiyati, I. (2017b). Kebijakan Manajemen Transportasi Darat Dan Dampaknya Terhadap Perekonomian Masyarakat Di Kota Depok. Jurnal Manajemen Transportasi Dan Logistik. https://doi.org/10.25292/j.mtl.v3i1.140

[3] Santos, G., Behrendt, H., \& Teytelboym, A. (2010). Part II: Policy instruments for sustainable road transport. Research in Transportation conomics.

https://doi.org/10.1016/j.retrec.2010.03.002
[4] Direktorat Jenderal Perhubungan Darat. 2015. Kebijakan Transportasi Perkotaan. Diunggah melalui laman http://www.hubdat.web.id/kebijakan/30-kebijakan-transportasi perkotaan.

[5] Biro Komunikasi dan Informasi Publik. (2011). Pemerintah Upayakan Pembenahan Transportasi Perkotaan dengan Push and Pull Policy. Kementerian Perhubungan Republik Indonesia.

[6] Zico, Nurrashid Priharseno. 2013. "'Push and Pull", Teori Kurangi Kemacetan Jakarta", https://megapolitan.kompas.com/ $\mathrm{read} / 2013 / 03 / 20 / 15544370 / . P u s h$ and.Pull Teori Kurangi Kemacetan Jakarta.

[7] Sharma \& Kumar, Shiv. (2012). Impact of Transportation System on Environment in Developing Countries "A Review". IJRREST: International Journal of Research Review in Engineering Science and Technology (ISSN 2278- 6643) | Volume-1 Issue-2, September 2012.

[8] Siburian, Giovanni. (2016). Analisis Pengaruh Transportasi Darat Terhadap Pertumbuhan Ekonomi Di Indonesia. Universitas Diponegoro Semarang. Diakses pada tanggal 18 Agustus $\quad 2018$ di laman http://eprints.undip.ac.id/49086/1/04_SIBURIAN.pdf

Tamin, Ofyar Z. (2000). Perencanaan dan Pemodelan Transportasi. Bandung. Penerbit ITB.

[9] Hengkeng, Hoin. 2015. Analisis Peran Retribusi Transportasi Darat terhadap Perekonomian Di Kabupaten Poso, 9 e-Jurnal Katalogis, Volume 3 Nomor 8, Agustus 2015 hlm 28-37 ISSN: 2302-2019.

[10] Regi, Yanuar. (2018). Kemacetan Jakarta Diatasi dengan Konsep Pull dan Push. https://jakarta.bisnis.com/read/20180416/77/784836/kemacetanjakarta-diatasi-dengan-konsep-pull-dan-push.

[11] Mulley, C., \& Tsai, C. H. (Patrick). (2016). When and how much does new transport infrastructure add to property values? Evidence from the bus rapid transit system in Sydney, Australia. Transport Policy. https://doi.org/10.1016/j.tranpol.2016.01.011. 